\title{
The Influence of Power Sense on Cooperation: The Mediating Effect of Perceived Control and the Moderating Effect of Dominance Motivation
}

\author{
Chi Yang, Yaozhong Liu, Haijin Chen \\ School of Management, Jinan University, Guangzhou, China \\ Email:yckobe@163.com
}

How to cite this paper: Yang, C., Liu, Y. Z., \& Chen, H. J. (2018). The Influence of Power Sense on Cooperation: The Mediating Effect of Perceived Control and the Moderating Effect of Dominance Motivation. Psychology, 9, 1065-1080.

https://doi.org/10.4236/psych.2018.95067

Received: March 28, 2018

Accepted: May 21, 2018

Published: May 25, 2018

Copyright (c) 2018 by authors and Scientific Research Publishing Inc. This work is licensed under the Creative Commons Attribution International License (CC BY 4.0). http://creativecommons.org/licenses/by/4.0/

\begin{abstract}
Cooperation runs through all aspects of our work, study and life and it is an important driving force for the development of our society. This article focuses on the influence of power sense on cooperation and tries to explore the inherent mechanism. We used questionnaire and laboratory experiment to explore the influence of power sense on cooperation and its psychological mechanism. There are three studies in this article, the results of our studies proved that: 1) The individual's power sense is positively correlated with the tendency of cooperation; 2) power sense positively affects cooperation; 3 ) perceived control of individual plays an intermediary role between power and cooperation; 4) dominance motivation can effectively alleviate the effect of power sense on perceived control.
\end{abstract}

\section{Keywords}

Power Sense, Dominance Motivation, Perceived Control, Cooperation

\section{Introduction}

Power is a very important concept in both eastern and western cultures. It is the basic element of social hierarchy and has existed since the birth of human society (Magee \& Galinsky, 2008). Power exists not only at the interpersonal or organizational level, but also at the individual level. On the organizational level, power is variable of social structure. It is an asymmetrical control over resources (Fiske, 1993). Power is the ability of individuals to control the outcomes of others by providing or deducting resources (Keltner, Gruenfeld, \& Anderson, 2003; Galinsky, Gruenfeld, \& Magee, 2003). On the individual level, power is a perception, which related to the individual's perceived influence and control over his or 
her own resources without the social interference (Rucker, Galinsky, \& Dubois, 2012). In social interactions, power is an important factor that influences social relations (Fiske, 1993). Therefore, power has always been an important subject that many scholars have studied and discussed. In recent years, researchers have begun to pay attention to the psychological attributes of power and began to regard power sense as a subjective perception of power (Rucker, Galinsky, \& Dubois, 2012). In real life, power sense can have a tremendous impact on individual decisions and actions. There are many studies on the effects of power. Some studies focus on the negative effects of power sense. For example, power will increase self-interest behavior, suggest discounted behavior, and non-ethical behavior (Chen, Leechai, \& Bargh, 2001; Gruenfeld, Inesi, Magee, \& Galinsky, 2008; Kleef \& Keltner, 2008). At the same time, scholars are also concerned about the positive effects of the power sense, such as power that enhances overall thinking, creativity, and positive emotions (Smith \& Trope, 2006; Galinsky, Magee, Gruenfeld, Whitson, \& Liljenquist, 2008). As an important content of interpersonal interaction, cooperation has also been the focus of many scholars. The definition of cooperation is mainly divided into two categories. One definition focuses on behavioral aspects, emphasizing that cooperation is a form of behavior that can be affected by the environment or others (Deutsch, 1958; Bay-Hinitz, Peterson, \& Quilitch, 1994; Zhu, 1989). Other definitions of cooperation focus on psychological tendencies and believe that cooperation is a relatively stable trait and is not affected by factors such as the environment (Kelley \& Stahelski, 1970; Xie, Yu, Chen, \& Chen, 2006). Nowadays, researchers are increasingly studying the relationship between power and cooperation, but most empirical research have drawn inconsistent conclusions. Some scholars believe that power may lead to more cooperation, and their research found that strong groups are more cooperative in asymmetric social dilemmas (Van Dijk \& Wilke, 1995; De Cremer \& Tyler, 2007). There are also studies which show that in asymmetrical social dilemmas, vulnerable groups are more cooperative (Kimbrough, Sheremeta, \& Shields, 2014; Avrahami, Kareev, Todd, \& Silverman, 2014). We believe that the cooperation effect of power is affected by many factors, and there may be multiple paths that power sense can influence cooperation. We need to explore the internal mechanisms of the influence of power sense on cooperation.

\subsection{The Approach-Inhibition Theory of Power}

In 2003, Keltner et al. combined the effect of power and the approach-inhibition system of behavior for the first time, and proposed the approach-inhibition theory of power. The theory holds that high power can activate the individual's behavior approach system (BAS), while low power activates the individual's behavior inhibition system (BIS). The activation of behavior approach system and behavior inhibition system influence individuals' behaviors, emotions and cognition (Wei \& Yu, 2009). When a high power sense may activates BAS, it may increase the individual's sensitivity for harvesting, leading individuals to be 
more inclined to seek reward clues in the environment, appearing more approach behavior (Carver \& White, 1994; Higgins, 1997). Conversely, a low power sense may activate BIS, and it may increase individuals' sensitivity to loss and potential punishment, leading individuals to be more inclined to focus on threat cues in the environment, and more inhibition behavior (Carver \& White, 1994). This theory is supported by many empirical studies. High-powered people are more inclined to express their feelings (Berdahl \& Martorana, 2006), have a more active attitude towards risk (Magee, Galinsky, \& Gruenfeld, 2007), and easier to take risks (Anderson \& Galinsky, 2010), they are more confident in their own judgment (See, Morrison, Rothman, \& Soll, 2011); and high-powered people tend to be more persuasive (Lammers, Dubois, Rucker, \& Galinsky, 2013). The approach-inhibition theory of power holds that people with different power construct their perceptions of the social environment in different ways, individual with high power will construct his/her perception of the social environment with automatic social cognition, while individual with low power will construct his/her perception of the social environment with analytical social cognition.

\subsection{Power Sense and Cooperation}

\subsubsection{Relationship between Power Sense and Cooperative Personality}

According to the definition of cooperation we mention earlier in this article (Deutsch, 1958; Bay-Hinitz et al., 1994; Zhu, 1989; Kelley \& Stahelski, 1970; Xie et al., 2006), we can find that cooperation includes behavior and personal traits. Therefore, if we want to understand the relationship between power sense and cooperation, we need to study the relationship between power sense and individual's cooperative personality. The individual's general power sense is a state of mind that perceives one's own ability to influence or control others (Rucker, Galinsky, \& Dubois, 2012). Individuals with high power sense can perceive more control and lower uncertainty. Such individuals have a higher tendency to be cooperative. At the same time, there are also empirical studies showing that in a social dilemma, the strong groups tend to be more cooperative (De Cremer \& Tyler, 2007). Therefore, we assume that there is a positive correlation between the power sense and the cooperative personality.

\subsubsection{The Influence of Power Sense on Cooperation}

According to the approach-inhibition theory of power (Keltner et al., 2003), the individuals with high power sense may pay more attention to future benefits than loss and threat, so they are more likely to cooperate. In addition, empirical study have also found that when personal interests and organizational interests are in conflict, high-powered individuals tend to sacrifice individual interests to protect organizational interests (Galinsky et al., 2003). Similarly, there are researchers who have discovered that when a group is threatened or offended by an outside group, the leader is more likely to work hard for the interests of the group while placing personal self-interest on a secondary position (Maner \& 
Mead, 2010; Mead \& Maner, 2012). Therefore, we assume that power sense will positively affect cooperation.

\subsubsection{Psychological Mechanism of the Influence of Power Sense on Cooperation}

According to the definitions of power we mention earlier in this article (Fiske, 1993; Keltner et al., 2003; Galinsky et al., 2003), we can see that many definitions of power regarded control as the essence of power, they think that power is the asymmetric control of the results of oneself or others (Keltner et al., 2003; Fast, Sivanathan, Mayer, \& Galinsky, 2012). This shows that perceived control is the core element of power (Fiske, 1993; Wei \& Yu, 2009). Many studies have shown that power increases the perceived control: The study found that people with higher economic status (Lachman \& Weaver, 1998) and members of dominant groups feel that they have more control over the future than others (Guinote, Brown, \& Fiske, 2006). Fast et al. (2009) used empirical research to ascertain that power can indeed improve perceived control, and that the perceived control plays an intermediary role in the relationship between power and optimism, self-esteem, and action-oriented. Therefore, we assume that the perceived control plays an intermediary role in the influence of power sense on cooperation.

Dominance motivation comes from the individual achievement motivation model proposed by Cassidy and Lynn in 1989. It means that individual tends to use force or manipulate organizational resources to gain influence. In the individual achievement motivation model, dominance motivation and prestige motivation are two independent dimensions. Prestige motivation means that individual tends to gain influence through the respect of members of the organization (Cassidy \& Lynn, 1989). Individuals with high dominance motivation have higher desire for control of resources and outcomes, so we can say that they have a higher desire for control. Research on perceived control shows that individuals' desire for control significantly affects individuals' estimation of their ability of control. Individuals with high control desires tend to overestimate their ability of control. They cannot achieve the desired result because of overestimating their ability of control, which might lead to a reduction of perceived control (Burger, 1986), while the performance of individual with low dominance motivation is just the opposite. At the same time, the legitimacy and rationality of power will also affect the effect of power. The approach-inhibition theoryof power (Keltner et al., 2003) believed that legitimacy moderates the effects of power, and this view has also been supported by empirical research: Lammers et al. (2010) use four experiments demonstrate that this link between power and approach is broken when the power relationship is illegitimate. The study of Guan Yanhua et al. (2016) shows that power can positively affect the perceived control of individuals, and they also find that there is an interaction between the rationality of power and the level of power, which means that the rationality of power can moderate the effects of power. According to the definition of domin- 
ance motivation, individuals tend to gain influence through force and selfish manipulation of organizational resources. Such power will be lacking in legitimacy and rationality because the power is not granted voluntarily subordinates, this will lead to a reduction of perceived control. Therefore, we hypothesize that the dominance motivation can effectively moderate the influence of the power sense on the perceived control.

This article uses three studies to explore the relationship between power sense and cooperation and its psychological mechanism. There are four core assumptions. H1: Power sense is positively related to the cooperative personality; $\mathrm{H} 2$ : Power sense positively affects cooperation; H3: Perceived control plays a mediating role in the process of the influence of power sense on cooperation; $\mathrm{H} 4$ : Dominant motivation can be effective moderate the influence of power sense on the perceived control. At different levels of dominance motivation, power sense has different effect on perceived control. Study 1 examines the relationship between power sense and cooperative personality; Study 2 explores the effect of power sense on cooperation by using laboratory experiments; Study 3 explores the psychological mechanism of power sense affecting cooperation. We examine the mediating effect of perceived control and the moderating effect of dominance motivation by using laboratory experiments.

\section{Study 1: The Relationship between Power Sense and Cooperative Personality}

\subsection{Purposes}

We used a scale of personal power and a scale of cooperative personality to investigate the relationship between power sense and cooperative personality.

\subsection{Methods}

\subsubsection{Participants}

We send 200 questionnaires to the participants (200 Chinese university students, 106 males and 94 females, between 18 and 30 years old). Participants were physically and mentally healthy and had not participated in similar experiments before.

\subsubsection{Measurement}

1) Scale of Personal Power

We used the scale of personal power developed by Anderson, John and Keltner (2012), deemed to have good reliability and validity. The scale has 8 items, such as "I think I was very influential." The participants completed the scale by self-assessment. Before the formal publication of this scale, it has been cited by many articles (Chen, Langner, \& Mendoza-Denton, 2009; Harms, Roberts, \& Wood, 2007).

2) Scale of cooperative personality

This scale is the subscale of the Scale of Cooperative and Competitive Perso- 
nality developed by Xie et al. in 2006. The subscale of cooperative personality has three dimensions: inclusiveness, reciprocity and willingness to group. This subscale often used to measure individual general cooperation tendencies. There are 13 items in this scale which divided into 3 dimensions: inclusiveness, reciprocity and willingness to the group.

\subsection{Results}

We used Cronbach's Alpha coefficient to test the reliability of the scales. The alpha coefficient of the power sense $(\alpha=0.850)$ and cooperative personality ( $\alpha=$ 0.851 ) both exceed 0.70 . And we use SPSS to analyze the correlation of power sense and cooperative personality. The result showed a significant positive correlation between power sense and cooperative personality $(r=0.47, p<0.01)$. This means the higher score of power sense, the higher score of cooperative personality.

\section{Study 2: Experimental Research on the Influence of Power Sense on Cooperation}

\subsection{Purposes}

In study 1 , we used questionnaires to explore the relationship between power sense and cooperative personality. The result demonstrates that there is a significant positive correlation between power sense and cooperative personality. But we don't know whether power will affect cooperation. So we need manipulate individual's power sense to find out whether the manipulation of power sense will affect individual's cooperation. In study 2, we will use laboratory experiment to explore the influence of power sense on cooperation.

\subsection{Methods}

\subsubsection{Participants and Design}

Participants were 60 Chinese students ( 32 men, 28 women; Age: 18 - 28). This experiment is a between-participants design because we need to manipulate the power sense of each participant. Participants were assigned randomly to the powerful group and the powerless group. In the powerful group we will ask the participant to recall an incident in which he/her had power over another individual to activate his/her high level of power sense. In the powerless group we will ask the participant to recall an incident in which someone had power over he/she to activate his/her low level of power sense.

\subsubsection{Procedure}

Power sense was manipulated with recall task (Anderson \& Galinsky, 2010; Yan \& Zhu, 2016). Participants were asked to think and write about anexperience in their life. The instructions for the powerful group were as follows:

Please recall a particular incident in which you had power over another individual, by power we mean a situation in which you controlled the ability of 
another person to get something he or she wanted, or you were in a position to evaluate him/her/them. Please describe this situation: What happened, how you felt, etc.

The instructions for the powerless group were as follows:

Please recall a particular incident in which someone had power over you, by power we mean a situation in which he/she controlled the ability of you to get something you wanted, or he/she was in a position to evaluate you. Please describe this situation: What happened, how you felt, etc.

After the recall test, participants completed a measurement developed by Huang et al. (2011) to test the manipulation of participants' power sense. We used the score of this measurement as the indicator of participants' power sense.

After the measurement, participant completed an adapted version of public goods dilemmato verify the participants' level of cooperation:

We need two persons to complete this task. One is participant, the other person is assistance who pretend to be another participant. Each of them got a free campus card with 30 yuan. They can use it to buy things in campus supermarket.

If the participant uses up 30 yuan in this campus card, he/she needs to recharge at his/her own expense. Or, they can transfer some money $(0-30)$ to the public account for group sharing in advance. After receiving the transfer request, the public account will calculate the sum of the money from two persons and generate a $50 \%$ profit. The sum of the money from two persons and profit will evenly distributed to the two persons' personal campus card. Participants are asked to write down the amounts that they are willing to transfer to the public accounts. The values filled in by the participants can regard as the indicator of the participants' cooperation behavior (Liu \& Hao, 2015; Wang \& Chen, 2011; $\mathrm{Hu}, 2008)$.

\subsection{Results}

Result of independent sample t test demonstrated that recall task can effectively manipulate participants' power sense. The score of powerful group in manipulation measurement was significantly higher than powerless group $(t=8.56, p<$ 0.001). Another result of independent sample t test demonstrated that the there was a significant difference in the indicator of cooperation between powerful group and powerless group $(t=6.46, p<0.001)$. Thus, the participants from powerful group were more likely to cooperate than participants from powerless group. According to the result of regression analysis (Table 1 ), we can see that $B$ $=0.65$, which means power sense will positively affect cooperation. This model can explain the $20 \%$ variation of cooperation.

\section{Study 3: The Psychological Mechanism of the Influence of Power Sense on Cooperation}

\subsection{Purposes}

In study 2 , we demonstrated that power sense will positively affect cooperation. 
Table 1. Regression analysis of power sense and cooperation.

\begin{tabular}{cccccc}
\hline & $B$ & $t$ & $R^{2}$ & Adjusted $R^{2}$ & $F$ \\
\hline $\begin{array}{c}\text { Power Sense } \\
\text { constant }\end{array}$ & 0.65 & $3.94^{* * *}$ & 0.21 & & $15.53^{* * *}$ \\
\hline
\end{tabular}

Note: ${ }^{\star} p<0.05,{ }^{* *} p<0.01,{ }^{* * *} p<0.001$.

However, our understanding of the psychological mechanisms is still limited. Therefore, we need to do more research to explore the psychological mechanism of the influence of power sense on cooperation. In study 3, we manipulated the power sense through the role-playing method. In the experiment, we measured participant's perceived control and dominance motivation in order to explore the psychological mechanism of the influence.

\subsection{Methods}

\subsubsection{Participants and Design}

Participants were 90 Chinese students (45 men, 45 women; Age: 18 - 28). This experiment is a between-participants design. Participants were assigned randomly to the powerful group and the powerless group. After manipulation of power sense (role-playing), each participant completed a questionnaire of dominance motivation (Cassidy \& Lynn, 1989), questionnaire of perceived control (Lachman \& Weaver, 1998) and public goods dilemma.

\subsubsection{Procedure}

First, we constructed a virtual situation that two persons have to work together to complete a task (role-playing method). One is participant, the other person is assistance who pretend to be another participant. And then arrange participant to act as superiors (powerful group) or subordinate (powerless group). The superior can make a plan for the task and direct the subordinate to complete the task, and the superiors can evaluate the subordinate performance and decide how much bonus the subordinate can get. The subordinate can only obey the instructions of the superior (Anderson \& Berdahl, 2002). After that, participants completed a measurement developed by Huang et al. (2011) to test the manipulation of participants' power sense. We used the score of this measurement as the indicator of participants' power sense. And then participant need to completed the questionnaire of dominance motivation (Cassidy \& Lynn, 1989), questionnaire of perceived control (Lachman \& Weaver, 1998) and the adapted version of public goods dilemma (the same as study 2).

\subsection{Results}

Result of independent sample $t$ test demonstrated that role-playing can effectively manipulate participants' power sense. The score of powerful group in manipulation measurement was significantly higher than powerless group $(t=$ $10.72, p<0.001)$. 


\subsubsection{The Mediating Effect of Perceived Control}

According to the results of the correlation analysis (Table 2), we can see that power sense, perceived control and cooperation are both significant correlative to each other.

We used stepwise regression to test the mediating effect of perceived control. According to the result of stepwise regression (Table 3), the regression coefficient between power sense and cooperation is 0.43 , which can explain $18 \%$ of the variation of the variance of the cooperation. The regression coefficient between power sense and perceived control is 0.42 , which can explain $18 \%$ of the variation of the variance of the perceived control. We put power sense and perceived control into the model of cooperation, we can see that the regression coefficient between power sense and cooperation reduces to $0.25(t=2.10, p<0.05)$ which is still significant. The regression coefficient between perceived control and cooperation is also significant ( $\mathrm{B}=0.41, t=7.41, p<0.001$ ). These results show that the mediating effect of perceived control is partial. According to the results we can draw a figure of the mediating effect (Figure 1).

In order to further examine the mediating effect of perceived control, we used Bootstrap tests to repeat sampling 5000 times and calculated $95 \%$ confidence intervals. The result of the Bootstrap (Table 4) shows that the confidence interval of the mediating effect of perceived control is $[0.23,0.56]$, which does not include 0 , indicating that the mediating effect of perceived control is significant. Therefore, the mediating effect of perceived control is partial.

\subsubsection{The Moderating Effect of Dominance Motivation}

We used a hierarchical regression to examine the moderating effect of dominance motivation. First of all, to avoid the possibility of collinearity in the data, we decentralized the variables of power sense and dominance motivation in the hierarchical regression analysis. In the first step, we put perceived control and dominance motivation in the first tier, and in second step, we put the interaction terms of perceived control and dominance motivation in second tier. According to the result of hierarchical regression (Table 5), we can see that the main effect of power sense and dominance motivation on perceived control are both significant, and there is a significant interaction between power sense and dominance motivation $(t=2.39, p<0.05)$. This result shows that the moderating effect of dominance motivation is significant.

We used a simple slope test (Preacher, Curran, \& Bauer, 2006) to gain a clearer understanding of the moderating effect of dominance motivation. According to the average score of dominance motivation, the participants were divided into two groups, namely the high dominance motivation group (average one standard deviation above) and low dominance motivation group (average one standard deviation below). The result (Figure 2) shows that in high dominance motivation group (average one standard deviation above), the power sense has no significant effect on perceived control $(B=0.43, t=1.63, n s)$, but in low dominance motivation group (average one standard deviation below), the power 
Table 2. Correlation analysis of power sense, perceived control and cooperation.

\begin{tabular}{cccccc}
\hline variables & $M$ & $S D$ & Power Sense & Perceived Control & Cooperation \\
\hline Power Sense & 12.50 & 3.73 & 1 & & \\
Perceived Control & 55.20 & 8.19 & $0.42^{* *}$ & 1 & 1 \\
Cooperation & 18.22 & 5.39 & $0.43^{* *}$ & $0.69^{* *}$ & 1 \\
\hline
\end{tabular}

Note: ${ }^{*} p<0.05,{ }^{* *} p<0.01,{ }^{* * *} p<0.001$.

Table 3. Result of stepwise regression.

\begin{tabular}{cccc}
\hline variables & $\begin{array}{c}\text { Model 1 } \\
\text { (First Step) }\end{array}$ & $\begin{array}{c}\text { Model 2 } \\
\text { (Second Step) }\end{array}$ & $\begin{array}{c}\text { Model 3 } \\
\text { (Third Step) }\end{array}$ \\
\hline $\begin{array}{c}\text { Power Sense } \\
\text { Perceived Control }\end{array}$ & $0.43^{* * *}$ & $0.42^{* * *}$ & $0.25^{*}$ \\
$R^{2}$ & 0.18 & 0.18 & $0.41^{* * *}$ \\
Adjusted $R^{2}$ & 0.18 & 0.17 & 0.49 \\
$F$ & $20.36^{* * *}$ & $18.70^{* * *}$ & $43.87^{* * *}$ \\
\hline
\end{tabular}

Note: ${ }^{\star} p<0.05,{ }^{* *} p<0.01,{ }^{* * *} p<0.001$.

Table 4. Result of bootstrap test.

\begin{tabular}{cccc}
\hline & Effect Size & $S E$ & confidence interval \\
\hline Direct Effect & 0.25 & 0.12 & \\
Mediating Effect & 0.37 & 0.08 & {$[0.23,0.56]$} \\
\hline
\end{tabular}

Table 5. Result of hierarchical regression.

\begin{tabular}{|c|c|c|c|c|c|c|}
\hline & variables & $B$ & $t$ & $R^{2}$ & $\Delta R^{2}$ & $\Delta F$ \\
\hline \multirow[t]{3}{*}{ First Step } & & & & 0.38 & 0.37 & $26.62^{* * *}$ \\
\hline & Power Sense & 0.69 & $7.00^{* * *}$ & & & \\
\hline & Dominance Motivation & -0.53 & $-5.35^{\star * *}$ & & & \\
\hline \multirow[t]{2}{*}{ Second Step } & & & & 0.42 & 0.40 & $5.70^{*}$ \\
\hline & $\begin{array}{c}\text { Power Sense }{ }^{*} \text { Dominance } \\
\text { Motivation }\end{array}$ & 0.21 & $2.39^{*}$ & & & \\
\hline
\end{tabular}

Note: ${ }^{\star} p<0.05,{ }^{* *} p<0.01,{ }^{* * *} p<0.001$.

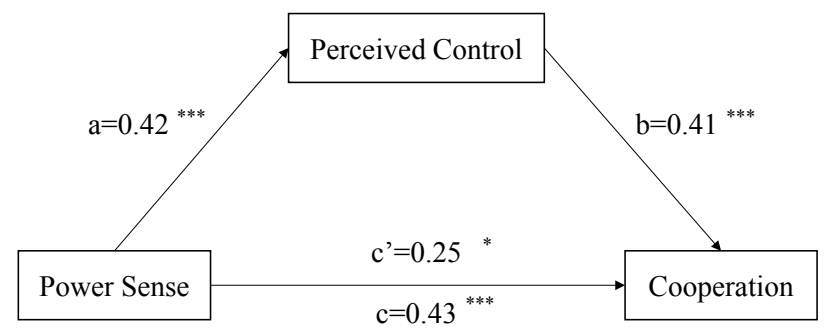

Figure 1. Mediating effect of perceived control. 


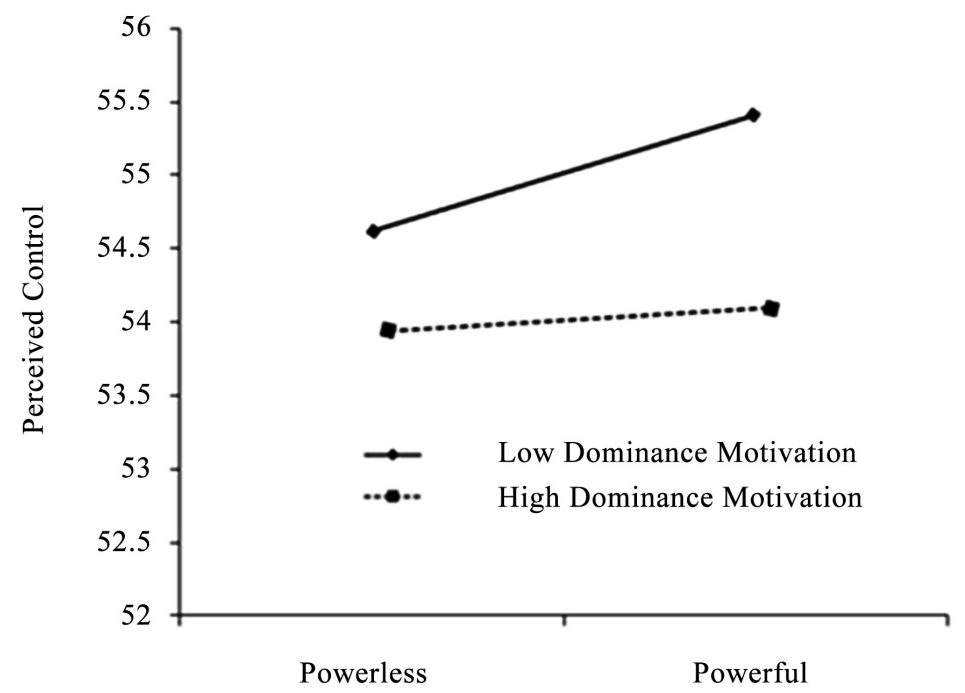

Figure 2. Result of interaction effect.

sense has significant effect on perceived control $(B=0.74, t=4.61, p<0.001)$. These results show that moderating effect of low dominance motivation is more significant.

\section{General Discussion}

\subsection{The Influence of Power Sense on Cooperation}

In Study 1 and Study 2, we explored the relationship between power sense and cooperation through questionnaires and experiments. In study 1 , a positive correlation was found between the power sense and the cooperative personality through questionnaires. In study 2 , we used recall task to manipulate participants' power sense, and observed the performance of participants in the cooperative task. The results of study 2 also showed that power sense will positively influence cooperation. And in study 3 we use another manipulation method of power sense (role-playing method) to confirmed the influence of power sense on cooperation. We can use the approach-inhibition theory of power to explain the positive effects of the power sense on cooperation. According to the approach-inhibition theory of power (Keltner et al., 2003), Individuals with higher power sense will activate the "behavior approach system", with the activation of BAS, individuals will pay more attention to the reward information in the environment or task. Individuals with high power sense will pay more attention to the returns that cooperation can bring. Therefore, individuals with high power sense will tend to be cooperative. As mentioned in the previous review, the relationship between power and cooperation has attracted the attention of many scholars. Different scholars have studied this relationship from different perspectives. Some scholars believe that power may lead to more cooperation, and their research found that strong groups are more cooperative in asymmetric social dilemmas (Van Dijk \& Wilke, 1995; De Cremer \& Tyler, 2007); and there are also studies show that in asymmetrical social dilemmas, vulnerable groups are 
more cooperative (Kimbrough et al., 2014; Avrahami et al., 2014). The results of this article are more consistent with the former that power sense can positively influence cooperation. Why are there different conclusions? In my opinion, first of all, this is related to methods used by researchers in specific empirical studies. Different studies use different methods to measure individuals' level of cooperation, this may lead to different result of the influence of power sense on cooperation. Second, some researchers use altruistic behavior as measurement indicators of cooperative behavior, and it is easier to conclude that power reduces cooperation. This article used a typical public goods dilemma as the indicator of cooperation. Cooperation in this task can obtain more resources, while competing with each other will reduce the profit, but when participants choose to cooperate, he/she must also bear the corresponding risks, which is more in line with our understanding of cooperation in everyday life. Last but not least, in the process of the influence of power on cooperation, there are still complex mechanisms that affect process. Therefore, we must explore the psychological mechanisms of this process so that we can understand more fully of this phenomenon.

\subsection{The Mediating Effect of Perceived Control}

In Study 3, we explored the mediating effect of perceived control. According to the review of researches, we can find that the study of the mediating mechanism of the power effect is rare and the conclusions are not consistent. Studies have found that positive emotions play an intermediary role between power and overconfidence decisions (Fast et al., 2012). Other studies believe that confidence can explain the negative effects of power, including suggesting discounts and inaccurate decisions (See et al., 2011). In this study, we consider perceived control as an important mediating role in the influence of power sense on cooperation. According to the results of Study 3, we confirmed the mediating effect of perceived control.

The mediating role of perceived control can also be incorporated into the approach-inhibition theory of power. The approach-inhibition theory of power proposed by Keltner et al. (2003) mentions that when people have power, their "behavior approach system" will be activated, and people will pay more attention to the reward information in the environment. So they will focus on rewards and overestimate the probability of positive outcomes in uncertain events, allowing individuals to experience higher perceived control over uncertain events. Many studies also show that individuals with higher economic status (Lachman \& Weaver, 1998) and members of social advantage groups (Guinote et al., 2006) experience a higher perceived control than other individuals. At the same time, the mediating role of perceived control has been supported by many empirical studies (Lachman \& Weaver, 1998; Guinote et al., 2006; Fast et al., 2009). However, as shown in the results in study 3 , the perceived control only partially mediates the relationship between power and cooperation, so we need to explore more variables to understand the mediating mechanism of the influence of power sense on cooperation. 


\subsection{The Moderating Effect of Dominance Motivation}

In Study 3, we used the questionnaire of dominance motivation to measure the participants' dominance motivation. We found that dominance motivation can effectively moderate the influence of the power sense on perceived control. As there are many inconsistent research conclusions in power effects, more and more scholars have tried to find moderating variables of power effects, which provides basis for reasonable interpretation of inconsistent research conclusions.

We know that different individuals have different power sense and dominance motivation. Different levels of dominance motivation can affect the power effects. The approach-inhibition theoryof power (Keltner et al., 2003) mentions that legality may moderate the effects of power, which has also been supported by empirical research (Lammers et al., 2010). The study of Guan Yanhua et al. (2016) shows that there is an interaction between the rationality of power and the level of power on perceived control. According to the definition of dominance motivation, individuals with high dominance motivation gain power through force and selfish manipulation of organizational resources. Such power will be lacking in legitimacy and rationality, leading to a reduction in the perceive control of individuals with high power sense. Through Study 3, we can understand that dominance motivation can moderate the influence of power sense on perceived control.

\section{Summary}

\subsection{Significance}

\subsubsection{Theoretical Significance}

At present, there are no unified conclusions about the influence of power sense on cooperation. In this article, we used three studies to explore the relationship between power sense and cooperation from different perspectives which contained not only questionnaires, but also experimental studies with high internal validity. This article explores the internal mechanism of the influence of power sense on cooperation, providing empirical support for power theory, and providing basis for subsequent theoretical expansion.

\subsubsection{Practical Significance}

Nowadays, individuals within an organization and group will have a different degree of power; these will significantly affect the individual's cooperation. The results of this article can help us to predict cooperative performance of individuals with different powers. In addition, cooperation is a major issue in today's society; we need to improve the levels of cooperation. This article discusses the moderating role of dominance motivation, helps us to find the ways to promote social cooperation. It also has a certain degree of inspiration for school education and government organizations.

\subsection{Prospects}

Although we explored the mechanism of the influence of power sense on coop- 
eration, but the influence of power on cooperation is a very huge research field, involving the influence of multiple factors such as individuals and scenarios, this article only focus on the mediating effect of perceived control and moderating effect of dominance motivation, which makes the results of this article have certain limitations. At the same time, most of the participants we selected are student, which will also reduce the external validity. In addition, the article also found that the perceived control only played a partial mediating role between power sense and cooperation. This shows that there are still other variables affecting the relationship between power sense and cooperation. Future research may continue to explore the other possible mediating variables.

\section{References}

Anderson, C., \& Berdahl, J. L. (2002). The Experience of Power. Journal of Personality \& Social Psychology, 83. https://doi.org/10.1037/0022-3514.83.6.1362

Anderson, C., \& Galinsky, A. D. (2010). Power, Optimism, and Risk-Taking. European Journal of Social Psychology, 36, 511-536. https://doi.org/10.1002/ejsp.324

Anderson, C., John, O. P., \& Keltner, D. (2012). The Personal Sense of Power. Journal of Personality, 80, 313. https://doi.org/10.1111/j.1467-6494.2011.00734.x

Avrahami, J., Kareev, Y., Todd, P. M., \& Silverman, B. (2014). Allocation of Resources in Asymmetric Competitions: How Do the Weak Maintain a Chance of Winning? Journal of Economic Psychology, 42, 161-174. https://doi.org/10.1016/j.joep.2013.11.002

Bay-Hinitz, A. K., Peterson, R. F., \& Quilitch, H. R. (1994). Cooperative Games: A Way to Modify Aggressive and Cooperative Behaviors in Young Children. Journal of Applied Behavioral Analysis, 27, 435-446. https://doi.org/10.1901/jaba.1994.27-435

Berdahl, J. L., \& Martorana, P. (2006). Effects of Power on Emotion and Expression during a Controversial Group Discussion. European Journal of Social Psychology, 36, 497-509. https://doi.org/10.1002/ejsp.354

Burger, J. M. (1986). Desire for Control and the Illusion of Control: The Effects of Familiarity and Sequence of Outcomes. Journal of Research in Personality, 20, 66-76. https://doi.org/10.1016/0092-6566(86)90110-8

Carver, C. S., \& White, T. L. (1994). Behavioral Inhibition, Behavioral Activation, and Affective Responses to Impending Reward and Punishment: The Bis/Bas Scales. Journal of Personality \& Social Psychology, 67, 319-333. https://doi.org/10.1037/0022-3514.67.2.319

Cassidy, T., \& Lynn, R. (1989). A Multifactorial Approach to Achievement Motivation: The Development of a Comprehensive Measure. Journal of Occupational Psychology, 62, 301-312.

Chen, S., Langner, C. A., \& Mendozadenton, R. (2009). When Dispositional and Role Power Fit: Implications for Self-Expression and Self-Other Congruence. Journal of Personality \& Social Psychology, 96, 710-727. https://doi.org/10.1037/a0014526

Chen, S., Leechai, A. Y., \& Bargh, J. A. (2001). Relationship Orientation as a Moderator of the Effects of Social Power. Journal of Personality \& Social Psychology, 80, 173-187. https://doi.org/10.1037/0022-3514.80.2.173

De Cremer, D., \& Tyler, T. R. (2007). The Effects of Trust in Authority and Procedural 
Fairness on Cooperation. Journal of Applied Psychology, 92, 639-649. https://doi.org/10.1037/0021-9010.92.3.639

Deutsch, M. (1958). Trust and Suspicion. Journal of Conflict Resolution, 2, 265-279. https://doi.org/10.1177/002200275800200401

Fast, N. J., Gruenfeld, D. H., Sivanathan, N., \& Galinsky, A. D. (2009). Illusory Control: A Generative Force Behind Power's Far-Reaching Effects. Psychological Science, 20, 502. https://doi.org/10.1111/j.1467-9280.2009.02311.x

Fast, N. J., Sivanathan, N., Mayer, N. D., \& Galinsky, A. D. (2012). Power and Overconfident Decision-Making. Organizational Behavior \& Human Decision Processes, 117, 249-260. https://doi.org/10.1016/j.obhdp.2011.11.009

Fiske, S. T. (1993). Controlling Other People. The Impact of Power on Stereotyping. American Psychologist, 48, 621. https://doi.org/10.1037/0003-066X.48.6.621

Galinsky, A. D., Gruenfeld, D. H., \& Magee, J. C. (2003). From Power to Action. Journal of Personality \& Social Psychology, 85, 453-466. https://doi.org/10.1037/0022-3514.85.3.453

Galinsky, A. D., Magee, J. C., Gruenfeld, D. H., Whitson, J. A., \& Liljenquist, K. A. (2008). Power Reduces the Press of the Situation: Implications for Creativity, Conformity, and Dissonance. Journal of Personality \& Social Psychology, 95, 1450-1466. https://doi.org/10.1037/a0012633

Gruenfeld, D. H., Inesi, M. E., Magee, J. C., \& Galinsky, A. D. (2008). Power and the Objectification of Social Targets. Journal of Personality \& Social Psychology, 95, 111-127. https://doi.org/10.1037/0022-3514.95.1.111

Guan, Y. H., Chi, Y. K., Wang, M. Y., \& Jiang, Y. (2016). The Effect of Power Priming on the Illusion of Control. Psychological Science, 39, 418-423.

Guinote, A., Brown, M., \& Fiske, S. T. (2006). Minority Status Decreases Sense of Control and Increases Interpretive Processing. Social Cognition, 24, 169-186.

https://doi.org/10.1521/soco.2006.24.2.169

Harms, P. D., Roberts, B. W., \& Wood, D. (2007). Who Shall Lead? An Integrative Personality Approach to the Study of the Antecedents of Status in Informal Social Organizations. Journal of Research in Personality, 41, 689-699.

https://doi.org/10.1016/j.jrp.2006.08.001

Higgins, E. T. (1997). Beyond Pleasure and Pain. American Psychologist, 52, 1280-1300. https://doi.org/10.1037/0003-066X.52.12.1280

$\mathrm{Hu}, \mathrm{Z}$. Y. (2008). The Influence of Cooperation Behavior in Repeated N-Person Public Goods Experiments. Shanghai: Tongji University.

Huang, L., Galinsky, A. D., Gruenfeld, D. H., \& Guillory, L. E. (2011). Powerful Postures versus Powerful Roles: Which Is the Proximate Correlate of Thought and Behavior? Psychological Science, 22, 95-102. https://doi.org/10.1177/0956797610391912

Kelley, H. H., \& Stahelski, A. J. (1970). Social Interaction Basis of Cooperators' and Competitors' Beliefs about Others. Journal of Personality and Social Psychology, 16, 66-91. https://doi.org/10.1037/h0029849

Keltner, D., Gruenfeld, D. H., \& Anderson, C. (2003). Power, Approach, and Inhibition. Psychological Review, 110, 265-284. https://doi.org/10.1037/0033-295X.110.2.265

Kimbrough, E. O., Sheremeta, R. M., \& Shields, T. W. (2014). When Parity Promotes Peace: Resolving Conflict between Asymmetric Agents. Journal of Economic Behavior \& Organization, 99, 96-108. https://doi.org/10.1016/j.jebo.2013.12.021

Kleef, G. A. V., \& Keltner, D. (2008). Power, Distress, and Compassion Turning a Blind Eye to the Suffering of Others. Psychological Science, 19, 1315-1322. 
https://doi.org/10.1111/j.1467-9280.2008.02241.x

Lachman, M. E., \& Weaver, S. L. (1998). The Sense of Control as a Moderator of Social Class Differences in Health and Well-Being. Journal of Personality \& Social Psychology, 74, 763-773. https://doi.org/10.1037/0022-3514.74.3.763

Lammers, J., Dubois, D., Rucker, D. D., \& Galinsky, A. D. (2013). Power Gets the Job: Priming Power Improves Interview Outcomes. Journal of Experimental Social Psychology, 49, 776-779. https://doi.org/10.1016/j.jesp.2013.02.008

Lammers, J., Stapel, D. A., \& Galinsky, A. D. (2010). Power Increases Hypocrisy: Moralizing in Reasoning, Immorality in Behavior. Psychological Science, 21, 737-744. https://doi.org/10.1177/0956797610368810

Liu, C. J., \& Hao, F. (2015). Decision Making in Asymmetric Social Dilemmas: A Dual Mode of Action. Advances in Psychological Science, 23, 1-10. https://doi.org/10.3724/SP.J.1042.2015.00001

Magee, J. C., \& Galinsky, A. D. (2008). Social Hierarchy: The Self-Reinforcing Nature of Power and Status. Academy of Management Annals, 2, 351-398. https://doi.org/10.5465/19416520802211628

Magee, J. C., Galinsky, A. D., \& Gruenfeld, D. H. (2007). Power, Propensity to Negotiate, and Moving First in Competitive Interactions. Personality \& Social Psychology Bulletin, 33, 200-212. https://doi.org/10.1177/0146167206294413

Maner, J. K., \& Mead, N. L. (2010). The Essential Tension between Leadership and Power: When Leaders Sacrifice Group Goals for the Sake of Self-Interest. Journal of Personality \& Social Psychology, 99, 482-497. https://doi.org/10.1037/a0018559

Mead, N. L., \& Maner, J. K. (2012). On Keeping Your Enemies Close: Powerful Leaders Seek Proximity to Ingroup Power Threats. Journal of Personality \& Social Psychology, 102, 576-591. https://doi.org/10.1037/a0025755

Rucker, D. D., Galinsky, A. D., \& Dubois, D. (2012). Power and Consumer Behavior: How Power Shapes Who and What Consumers Value. Journal of Consumer Psycholo$g y$, 22, 352-368. https://doi.org/10.1016/j.jcps.2011.06.001

See, K. E., Morrison, E. W., Rothman, N. B., \& Soll, J. B. (2011). The Detrimental Effects of Power on Confidence, Advice Taking, and Accuracy. Social Science Electronic Publishing, 116, 272-285. https://doi.org/10.1016/j.obhdp.2011.07.006

Smith, P. K., \& Trope, Y. (2006). You Focus on the Forest When You're in Charge of the Trees: Power Priming and Abstract Information Processing. Journal of Personality \& Social Psychology, 90, 578-596. https://doi.org/10.1037/0022-3514.90.4.578

Van Dijk, E., \& Wilke, H. (1995). Coordination Rules in Asymmetric Social Dilemmas: A Comparison between Public Good Dilemmas and Resource Dilemmas. Journal of EXperimental Social Psychology, 31, 1-27. https://doi.org/10.1006/jesp.1995.1001

Wang, P., \& Chen, L. (2011). The Effects of Sanction and Social Value Orientation on Trust and Cooperation in Public Goods Dilemmas. Acta Psychologica Sinica, 43, 52-64.

Wei, Q. W., \& Yu, G. L. (2009). A Review of Social Cognitive Studies of Power. Advances in Psychological Science, 17, 1336-1343.

Xie, X. F., Yu, Y. Y., Chen, X., \& Chen, X. P. (2006). The Measurement of Cooperative and Competitive Personality. Acta Psychologica Sinica, 38, 116-125.

Yan, F., \& Zhu, H. W. (2016). Consumers' Sense of Power and Impulse Buying. Journal of Psychology, 48, 880-890.

Zhu, Z. X. (1989). Dictionary of Psychology. Beijing: Normal University Press. 